\title{
专访绿色化学领域代表人物一一刘志敏研究员
}

《物理化学学报》编辑部

北京大学化学与分子工程学院, 北京 100871

\section{Interview with the Leader of Green Chemistry: Prof. Zhimin Liu}

\author{
Editorial Office of Acta Physico-Chimica Sinica \\ College of Chemistry and Molecular Engineering, Peking University, Beijing 100871, China. \\ Email: whxb@pku.edu.cn \\ Published online: October 19, 2020.
}

随着世界人口不断增加, 资源短缺和环境问题日趋严重, 如何使化学在创造物质财富的同时, 保护 人类赖以生存的环境、节省资源和能源、实现可持续发展已成为不可回避的重大问题。绿色化学综合考 虑资源、能源和环境因素, 采用环境友好、可再生的原材料和溶剂, 通过高效催化反应和工业过程, 获 得环境友好的产品, 实现从源头上减少或消除污染, 以节约资源和能源, 实现可持续发展。绿色化学研 究始于上世纪九十年代, 经过二十余年的长足发展已经成为化学学科的前沿和必然发展方向, 引起了全 球的广泛关注。本期我们有幸采访了国内绿色化学领域的代表人物, 《物理化学学报》编委刘志敏研究 员, 为我们分享了她的研究经历及对国内外绿色化学行业的分析。

问题 1：刘老师，在您的科研生涯中从事过哪些方 面的研究? 您从什么时候开始从事绿色化学方面 的研究?

回答: 我的整个科研生涯都在从事绿色化学研究。 1993年，在师从杨光华先生和王仁安教授攻读博 士学位期间即开始涉足这个领域, 进行了黄酮类 化合物的超临界流体色谱分离及其热力学性质研 究。博士毕业后, 加入韩布兴研究员团队, 在做博 士后和副研究员期间, 主要从事超临界流体和离 子液体等绿色溶剂体系的热力学性质及其在纳米 材料合成中的应用研究工作。2007年成立独立课 题组以来, 研究方向集中于绿色溶剂体系中的化 学反应和绿色催化研究。近年来, 在离子液体体系 中二氧化碳和生物质的化学转化方面开展了大量 工作。

问题2: 请您简要介绍一下中国绿色化学的发展现 状, 以及绿色化学目前与哪些学科存在交叉研究。 回答: 我国人口众多, 技术相对落后, 环境污染严
重, 因此绿色化学研究和绿色技术研发对我国的 可持续发展意义重大。我国在绿色化学研究方面 起步较早。国家自然科学基金委员会、国家科技 部、中国科学院等设立不同类型的项目对绿色化 学进行了深入系统的研究、开发绿色技术, 目前越 来越多的绿色技术得到应用。二十多年来, 我国绿 色化学得到长足发展, 形成了一支在国际上具有 重要影响的科技队伍, 不少科研机构和高等院校 成立了绿色化学中心、研究所和实验室, 一些高等 学校设立了绿色化学课程。绿色化学是化学化工、 材料科学、物理、生物等学科相互交叉渗透的领 域, 绿色化学的发展将促进相关学科的发展及生 产生活方式的变革。

问题 3: 中国绿色化学的研究在国际上处于什么位 置? 我们的优势和劣势有哪些?

回答: 中国绿色化学研究在国际上处于先进行列, 在一些方面处于国际领先水平。我们的优势是政 府、学术界和企业都十分重视, 投入大量的科研经 
费支持, 有一支充满活力的高水平研究队伍。劣势 是仪器设备相对落后, 先进的仪器设备依赖进口; 由基础研究到技术转化还有很长的路, 新旧技术 的更替尚需时日。

问题 4: 目前绿色化学领域的发展存在的最大的挑 战有哪些? 未来有哪些发展趋势?

回答: 绿色化学领域存在诸多挑战, 最大的一些, 包括：1）石油、煤、天然气等化石资源和金属矿 物的清洁高效利用的新方法和新技术; 2) 二氧化 碳、生物质等可再生碳资源的资源化利用的绿色 途径；3) 可再生碳能源在化学中的高效利用等。

未来的发展趋势: 针对化石资源的转化利用, 发展清洁高效的新技术替代现有的落后技术路 线; 发展基于可再生资源的高效转化新路线, 如二 氧化碳和生物质转化制化学品、能源产品和材料 等; 发展基于绿色溶剂体系的化学新过程, 如离子 液体、超临界流体等绿色溶剂体系强化的化学过 程等; 发展废弃物资源化利用的新方法, 如由废旧 塑料、电子垃圾等制备化学品、能源产品和材料 等; 发展基于可再生能源的绿色新方法和新途径, 如利用光、电催化制备化学品和碳能源等。

问题5: 您能列举一些您的课题组正在进行的最重 要的几个项目吗?

回答: 我课题组目前承担着国家自然科学基金委 重大项目课题/重点项目/面上项目、国家重点研发 计划项目和中国科学院重点支持项目等, 涉及功 能离子液体设计及其化学热力学性质研究, 离子 液体中二氧化碳化学转化的物理化学问题研究以 及二氧化碳转化制备化学品等, 均是绿色化学研 究的重要内容。

问题 6: 您认为绿色化学发展和应用对我们的社 会、环境和经济会有哪些影响? 能否举几个通俗 的例子?

回答: 绿色化学发展将带来化工技术的重大变革, 保护生态环境, 促进经济发展, 是化学工业可持续 发展的必由之路。例如, 超临界流体技术在啤酒 花、咖啡因、精油等天然产物的萃取分离中得到应 用, 显示比传统有机溶剂提取技术更多的优点。离 子液体催化碳四烷基化技术可替代传统的酸催化 技术, 已经实现工业化。
问题7: 在您的科研道路中是否遇到过挫折或困难?

回答: 科研道路向来是不平坦的。我遇到的挫折是 曾经困于现状, 科研上没有突破, 对自己的能力产 生怀疑。那时期比较苦闪, 但又不能停下前行的脚 步。可能很多人都会遇到类似的情况吧, 如长跑中 的疲劳期。这时信念的力量让自己坚持下来, 而在 日复一日的坚持中, 磨练心志, 不断实现自我突 破, 科研上也有了进步。

问题8: 对国内同样开展绿色化学研究的课题组, 尤其是年轻的课题组长, 您有什么好的建议吗?

回答: 我国已经建立了完整的化学工业体系, 但存 在着技术落后和污染严重等问题, 而绿色化学是 解决这些问题的根本途径。在大力倡导绿色发展 的今天, 从事绿色化学研究的青年科技工作者大 有可为。建议从事绿色化学研究的年轻课题组长 们从基础研究和绿色技术研发两方面入手开展工 作：1）瞄准重大科学问题, 开展原创性工作。技 术之所以落后, 究其原因是基础研究薄弱, 因此要 找准科学问题, 进行攻关, 以基础研究推动技术发 展。2) 面向国家重大需求, 解决当前存在的卡脖 子问题。对于依赖进口的化工原材料, 我们要发展 自己的技术进行生产; 而对于落后的技术, 要发展 绿色新技术进行替代, 因此新技术研发是当务之 急。3) 要坚持自己的研究方向, 不追热点, 只争 朝夕, 潜心研究, 真正成为自己研究领域的专家。

问题9: 工作之余，您有什么兴趣爱好?

回答: 兴趣爱好还是比较广泛的, 只是工作之余的 时间太少。只能利用有限的工作之余时间, 做一些 健身运动, 尤其那些占时少、不需要特定场地的运 动, 如跑步、骑自行车、跳绳、练瑜伽等。

问题 10: 请您对国内的中文学术期刊的建设和发 展提出建议。

回答: 期刊是学术交流的重要平台, 中文期刊应兼 顾报道原始科研成果和广大中文读者人群的需 求。另外, 现代网络技术为学术交流提供了新模 式。建议中文学术期刊充分考虑网络时代读者群 的特点, 发展多模式的宣传交流方式, 如文字交 流、音频/视频交流等。而作者群中, 青年科研工 作者比较活跃, 可创建青年才俊专栏, 鼓励年轻作 者投稿。总之, 中文学术期刊要多元化、多样化, 以满足中国学者的需求。 


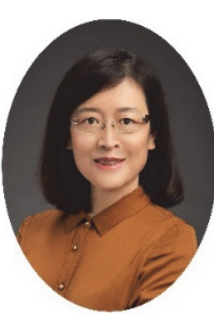

访问研究。

刘志敏, 中国科学院化学研究所研究员, 中国科学院大学岗位教授, 英国皇家化学 会会士，国家杰出青年科学基金获得者(2011), 科技部创新人才推进计划重点领域创新 团队负责人(2016)，“万人计划”科技创新领军人才(2018)。

1990 年和 1993 年于青岛化工学院分别获学士和硕士学位, 1997 年在中国石油大学 (北京)获博士学位, 1997-1999 年在中国科学院化学研究所从事博士后研究, 出站后留 在化学所工作至今。2003 年和 2006 年分别赴英国诺丁汉大学和日本东北大学开展合作

主要研究领域是绿色化学, 长期从事与超临界流体、离子液体等绿色溶剂相关的研究工作, 在基于 绿色溶剂特性调控制备催化材料和催化可再生碳资源化学转化方面取得重要研究成果。近年来, 研究方 向集中于离子液体催化和二氧化碳等可再生碳资源的资源化利用研究。迄今, 发表研究论文 300 余篇, 被引用 12000 余次，2015-2019 年连续入选爱思唯尔化学 “中国高被引学者” 榜单; 申请和获授权国家 发明专利 30 余件; 编著中文专著《二氧化碳化学转化》一书(中国科学出版社), 参与编写中英文专著 5 部。以第二完成人, 分别于 2007 年获北京市科学技术进步二等奖, 2011 年获国家自然科学二等奖。

现为中国化学会绿色化学专业委员会委员, 中国化工学会超临界流体技术专业委员会副主任委员和 离子液体专业委员会委员等; 担任Elsevier出版社Current Opinion in Green and Sustainable Chemistry期刊 主编, 任《物理化学学报》、《化工过程学报》编委等。 